\title{
Autologous PBTL CD19CAR-28 zeta
}

National Cancer Institute

\section{Source}

National Cancer Institute. Autologous PBTL CD19CAR-28 zeta. NCI Thesaurus. Code C78823.

A preparation of autologous peripheral blood T-lymphocytes (PBTL) that have been genetically modified to express the chimeric antigen receptor (CAR) anti-CD19/CD3 zeta chain fusion protein coupled to the intracellular signal domain of CD28 antigen, with potential immunostimulating and antineoplastic activities. Upon administration, autolog ous PBTL CD19CAR-28 zeta may stimulate host cytotoxic T lymphocyte (CTL) and antibody responses against CD19-expressing tumor cells, resulting in tumor cell lysis. CD19 antigen is a B-cell specific cell surface antigen expressed in all B-cell lineage malignancies. CD3 zeta is one of several membrane-bound polypeptides found in the Tcell receptor (TCR)/CD3 complex and regulates the assembly of complete TCR complexes and their expression on the cell surface. CD28 is essential for CD4+ T-cell proliferation, interleukin-2 production, and T-helper type-2 (Th2) development. 